\title{
ATF2, A Member of the CREB/ATF Family of Transcription Factors, in Chronic Stress and Consequent to Antidepressant Treatment: Animal Models and Human Post-Mortem Brains
}

\author{
D Laifenfeld*,', R Karry', E Grauer², E Klein' and D Ben-Shachar' \\ 'Laboratory of Psychobiology, The Department of Psychiatry, Rambam Medical Center and B. Rappaport Faculty of Medicine, Technion IIT, Haifa, \\ Israel; ${ }^{2}$ Department of Pharmacology, Israel Institute for Biological Research, Ness-Ziona, Israel
}

\begin{abstract}
The regulation of gene expression has been implicated in the etiology and treatment of depression. Transcription factors serve as the intermediates between intracellular cascades and gene expression, and may therefore be involved in the pathophysiology and pharmacotherapy of depression. We and others have previously reported an increase in the phosphorylation of the transcription factor CAMP response element binding protein (CREB) by antidepressants, alongside brain region-specific alterations in pCREB by stress. In the present study, we examined the expression of another member of the CREB/ATF family of transcription factors, ATF2, in the brains of rats chronically treated with two different antidepressants, and in rats 4 months after their exposure to prolonged stress. ATF2 phosphorylation was decreased by antidepressants and increased at the aftermath of prolonged stress, specifically in the frontal cortex. We also examined ATF2 expression in the ventral parieto-occipital region of post-mortem human brains of normal controls, depressed, bipolar, and schizophrenic patients, obtained from the Stanley Foundation Brain Consortium. No alterations were observed in the levels of ATF2. However, in the depressed group, the PATF2 levels were higher in unmedicated compared to medicated patients, suggesting an antidepressant-induced reduction in PATF2. We discuss the possible role of ATF2 in depression, and propose that an interplay between ATF2 and CREB, and possibly other transcription factors, determines the final gene expression pattern in the etiology and treatment of depression.
\end{abstract}

Neuropsychopharmacology (2004) 29, 589-597, advance online publication, 26 November 2003; doi: I 0. I038/sj.npp. I 300357

Keywords: stress; antidepressants; ATF2; plasticity; post mortem; CREB

\section{INTRODUCTION}

The past decade has witnessed an abundance of studies focusing on intracellular processes, leading to altered neuronal plasticity in the etiology and treatment of depression. Antidepressants have been found to activate several second messengers, including protein kinase C (Morishita and Aoki, 2002) and calcium-linked protein kinases (Consogno et al, 2001), with the most consistent findings pointing to antidepressant induction of the cAMP signaling pathway. Thus, the chronic administration of different antidepressants affects the binding of cAMP to various subunits of its substrate, PKA, and increases the latter's activity (Perez et al, 1989, 1991; Nestler et al, 1989). In addition, cAMP binding was reduced in post-

\footnotetext{
*Correspondence: Dr D Ben-Shachar, Laboratory of Psychobiology, Department of Psychiatry, Rambam Medical Center and B. Rappaport Faculty of Medicine, Technion ITT, POB 9649, Haifa 31096, Israel, Tel: + 9724 8295224, Fax: + 97248295220 ,

E-mail: shachar@tx.technion.ac.il

Received 01 July 2003; revised 30 September 2003; accepted 20 October 2003

Online publication: 23 October 2003 at http://www.acnp.org/citations/ Npp I0230303289/default.pdf
}

mortem brains of treated depressed patients who committed suicide (Lowther et al, 1997). Decreased cAMP signaling is observed in stress paradigms and consequent to dexamethasone treatment in rats (Makino et al, 1975). cAMP modulation impinges on the levels and function of the cAMP response element-binding protein (CREB), which has been found to present a complex pattern of alteration in the pharmacotherapy of depression, as well as in stress. Thus, antidepressants induce increases in the function (Nibuya et al, 1996; Duman et al, 1997) and expression (Laifenfeld et al, 2002a) of CREB in the rat hippocampus and frontal cortex. However, an effect opposite to that induced by antidepressants was found to be produced consequent to increased CREB expression in the nucleus accumbens (Pliakas et al, 2001). In addition, brain region-specific alterations are observed in the levels of CREB and its phosphorylation in post-mortem brains of depressed patients (Dowlatshahi et al, 1998; Laifenfeld et al, 2002b). Finally, various animal models of stress show pCREB decreases in the hippocampus and frontal cortex (Huang et al, 2002; Trentani et al, 2002; Laifenfeld et al, 2002a), and increases in the levels and activity of pCREB in the nucleus accumbens (Pliakas et al, 2001; Barrot et al, 2002). 
CREB is the prototypical member of the ATF/CREB transcription factors, which share a common cis-regulatory element (reviewed in De Cesare et al, 1999; Mayr and Montminy, 2001), termed as the cAMP response element (CRE). This element consists of the consensus sequence TGACGTCA, and has been implicated in the processes of plasticity, in as much as robust CREreporter gene expression can be detected in cortical neurons during developmental plasticity (Pham et al, 1999). In fact, members of the CREB/ATF2 family of transcription factors are considered important substrates of signals upstream of the activation of genes associated with neuronal growth and differentiation (Karin and Hunter, 1995). They therefore carry the potential to act as intermediates between extracellular stimuli, such as stressful events or therapeutic agents, gene modulation, and cellular alterations associated with depression. While CREB is expressed ubiquitously, other members of the family are more tissue specific. Thus, cAMP response element modulator (CREM) is highly expressed in the neuroendocrine tissues (Mayr and Montminy, 2001), and ATF2 is particularly abundant in the brain (Maekawa et al, 1989). CREB family members can also be differentiated according to their upstream signal transduction pathways. While CREB is activated mainly by cAMP, ATF2 is insensitive to cAMP (Flint and Jones, 1991), and is strongly induced by the p38/MAPK pathway (Ferrer et al, 2002; Ouwens et al, 2002).

Alongside the cAMP-CREB pathway, the involvement of additional signal transduction pathways in the treatment and etiology of depression has been suggested (Vaidya and Duman, 2001). Indeed, different groups of antidepressants have been shown to regulate the expression of a wide variety of genes (eg Ainsworth et al, 1998; Boyer et al, 1998; Vedder et al, 1999), demonstrating the involvement of additional transcription factors as intermediates between antidepressant-initiated intracellular cascades and gene regulation. ATF2 is a promising candidate, since it regulates two of the antidepressant-induced genes (Edelman et al, 2000; Suzuki et al, 2002), tyrosine hydroxylase (Nestler et al, 1990; Brady et al, 1992) and cell adhesion molecule L1 (Laifenfeld et al, 2002a). Moreover, the pathway upstream of ATF2, that is, the p38/MAPK pathway, is regulated by corticosterone on the one hand $(\mathrm{Li}$, 2001), and the mood stabilizer, lithium, on the other (Chuang et al, 2002). This, in turn, could lead to corresponding alterations in ATF2- and ATF2-transcribed genes. In the present study, we examined the mRNA and protein expression of ATF2 after chronic antidepressant treatment in rats, as well as in rats long after the termination of exposure to prolonged variable stress. The latter are used to model some aspects of depressive state, in that the paradigm serves to mimic the long-term effects of stressful life events, strongly implicated in the etiology depression (Holahan and Moos, 1991; Kendler et al, 1995; Willner, 1997).

In order to relate our findings to human depression, we also studied ATF2 expression in the ventral parietooccipital (BA 19) cortex of 59 human post-mortem brains of depressed, bipolar, or schizophrenic patients as well as controls, obtained from the Stanley Neuropathology Consortium.

\section{MATERIALS AND METHODS}

\section{Animals}

Male Sprauge-Dawley rats, 250-300 g at the beginning of the experiment, were housed in groups of five (prolonged stress paradigm) or six (antidepressant treatment) in metal mesh cages placed in a temperature-controlled environment $\left(21^{\circ} \mathrm{C} \pm 2\right)$ with lights on $0600-1800$. Food and water were available ad libitum unless otherwise noted. Animal care was in accordance with the institutional guidelines and approved by the institution's Animal Care and Use Committee.

\section{Antidepressant Treatment}

Rats were injected (i.p.) for 21 days with either fluoxetine $5 \mathrm{mg} / \mathrm{kg} /$ day or desipramine $10 \mathrm{mg} / \mathrm{kg} /$ day. Control animals were injected with an equivalent volume of saline. Animals were killed 1 day after the last antidepressant treatment by decapitation. The prefrontal cortex, hippocampus, and striatum were dissected on ice immediately following decapitation. Immediately after dissection, brain specimens were rapidly frozen in liquid nitrogen and stored at $-80^{\circ}$ until further analyses.

\section{Prolonged Variable Stress}

Rats were exposed for 6 weeks to variable unpredictable stressors including: cold exposure - rats were housed individually in small plastic cages and placed in a cold $\left(4^{\circ} \mathrm{C}\right)$ room for $1-4 \mathrm{~h}$ with (three sessions) or without (three sessions) room lights; shaking (seven sessions) - rats were placed in groups of five in a plastic cage placed on a shaker (approx. 140 movements/min) for $2-4 \mathrm{~h}$; restraint (seven sessions) - rats were placed individually in a small restrainer, which restricted all movement for up to $2 \mathrm{~h}$; hot plate (two sessions) - animals were placed individually on a hot plate set to $56^{\circ} \mathrm{C}$. The rat was removed immediately after it started licking its front paws (approx. $5 \mathrm{~s}$ ); foot shocks (three sessions) — rats were individually placed in a Skinner box and foot shocked twice $(0.8 \mathrm{~mA}$ for $3 \mathrm{~s})$ within a $10 \mathrm{~min}$ session. These same rats were reintroduced to the footshock environment (two sessions with no footshocks) for a 10 min session; blood sampling (once, through tail cuts). The order of stressors presentation, their duration, and the time of day they were applied were random within and between experiments. Rats were left undisturbed in between the various stress exposures. At 4 months after the termination of stress animals were decapitated, their brains were rapidly removed and dissected on ice for the prefrontal cortex, hippocampus, and striatum, promptly placed in liquid nitrogen, and stored in $-80^{\circ}$ until further analysis (Grauer, 1998).

\section{RT-PCR Analysis}

The expression of ATF2 was studied by using the RT-PCR technique (Figure 1a). Total RNA was isolated from frozen specimens using RNA STAT-60 kit (TEL-TEST, Inc.). cDNA was synthesized by first-strand reverse transcriptase reaction (RT) using Random Primer and M-MLV reverse transcriptase (Promega). Polymerase chain reaction amplification (PCR) of RT cDNA was performed at least twice for each sample at two different concentrations to confirm linear range, using FastStart Taq (Roche Molecular 
Table I Primer Sequences and PCR Conditions

\begin{tabular}{|c|c|c|c|c|c|c|c|}
\hline mRNA & & Primer sequence $\left(5^{\prime}-3^{\prime}\right)$ & $\begin{array}{c}\text { Denaturning } \\
\text { temperature } \\
\text { and time }{ }^{\circ} \mathbf{C}(\mathrm{s})\end{array}$ & $\begin{array}{c}\text { Annealing } \\
\text { temperature } \\
\text { and time }{ }^{\circ} \mathbf{C}(s)\end{array}$ & $\begin{array}{c}\text { Elongation } \\
\text { temperature } \\
\text { and time }{ }^{\circ} \mathbf{C}(s)\end{array}$ & $\begin{array}{c}\text { Number of } \\
\text { cycles }\end{array}$ & $\begin{array}{l}\text { Product } \\
\text { size (bp) }\end{array}$ \\
\hline ATF2 & $\mathrm{R}$ & TCAACTGCTGCTACACCAACTT & & & & & \\
\hline
\end{tabular}

All templates were initially denatured for $5 \mathrm{~min}$ at $95^{\circ} \mathrm{C}$, and after completing all cycles, were subjected to a final extension of 7 min at $72^{\circ} \mathrm{C}$.

Biochemicals). The sequences of PCR primers for ATF2 and $\beta$-actin were designed and synthesized according to the sequences obtained from Gene Bank (Table 1).

PCR products were assessed in a $2 \%$ agarose gel containing ethidium bromide with a PGEM DNA Marker (Pharmacia Biotech $\mathrm{AB}$ ). $\beta$-Actin was used for normalizing variations in aliquots taken for $\mathrm{RT}$ reaction and gel loading.

\section{Western Blot Analysis}

Frozen specimens were suspended in $10 \mathrm{mM}$ Tris-buffer $\mathrm{pH}$ 7.4 containing $250 \mathrm{mM}$ sucrose, $5 \mathrm{mM}$ EDTA, $0.5 \%$ NP40, and TM protease inhibitors cocktail. Following centrifugation, the supernatant ( 80 or $100 \mu \mathrm{g}$ total protein) was diluted $1: 1$ in electrophoresis sample buffer containing $20 \%(\mathrm{v} / \mathrm{v})$ glycerol, 4\% (w/v) SDS, $250 \mathrm{mM}$ Tris- $\mathrm{HCl}, \mathrm{pH} 6.8,10 \%$ (v/v) 2 -mercaptoethanol, and $0.5 \mathrm{mg} / \mathrm{ml}$ bromophenol blue. The protein sample was separated on $7.5 \%$ SDS acrylamide gel and transferred onto a nitrocellulose membrane. The quality of transfer was assayed by Ponceau staining. Following blocking (T-TBS containing 2\% BSA) of nonspecific binding sites, membranes were incubated at $4{ }^{\circ} \mathrm{C}$ overnight with ATF2/pATF2 antibody (Santa Cruz, sc-187, sc-8398, respectively) diluted 1:200, 1:100, respectively. After washing, blots were incubated for $1 \mathrm{~h}$ at room temperature with secondary antibody (anti-rabbit IgG, Santa Cruz; anti-mouse IgG, Santa Cruz), diluted 1:10000 in T-TBS. The blots were then developed with Amersham's ECL and exposed to an XLS Kodak film for 20-30 s (Figure 1b). The protein levels were analyzed three times for each sample. A single batch of protein of rat brain in three different concentrations was used as a positive control and for normalization. Protein concentration was measured using Bradford reagent (BIO-RAD).

\section{Human Post-Mortem Brains}

Frozen specimens, from the ventral parieto-occipital cortex (BA 19) of 59 human post-mortem brains, were donated by The Stanley Medical Research Institute's Brain Collection courtesy of Drs Michael B Knable, E Fuller Torrey, Maree J Webster, Serge Weis, and Robert H Yolken. The specimens were from 15 depressed patients, 15 bipolars, 14 schizophrenics, and 15 normal controls. Demographic data are found in Table 2.
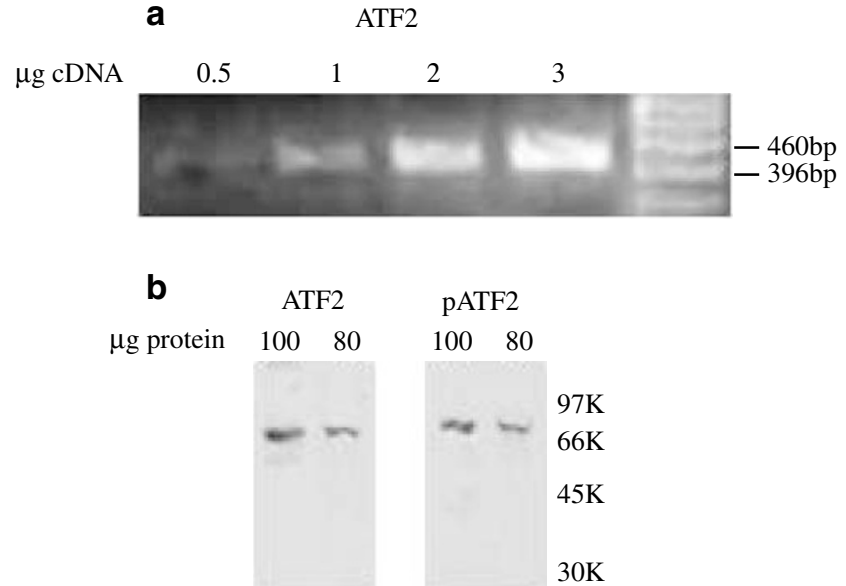

Figure I ATF2 mRNA (a) and ATF2/pATF2 protein (b) levels calibration. mRNA and protein from the rat brain were used to calibrate RT-PCR and Western blot analysis.

\section{Statistical Analysis}

The results were analyzed for normal distribution using the Kolmogorov-Smirnov test. Normally distributed data were then analyzed by one-way ANOVA followed by a post hoc Dunnett test with comparison to the control group. Data that were not distributed normally were analyzed by nonparametric Kruskal-Wallis test, followed by MannWhitney $U$-test. The $p$-values were adjusted according to the Bonferroni correction for multiple comparisons. Data from post-mortem brains (age, gender, laterality, PMI, cause of death, and brain $\mathrm{pH}$ ) were added as covariates and assessed by ANCOVA with mRNA or protein levels as the dependent variables.

\section{RESULTS}

Effects of Chronic Administration of Antidepressants on mRNA, Protein Levels, and Phosphorylation Levels of ATF2 in Rat Brain

ANOVA analysis, aimed at determining a difference in the levels of phosphorylated ATF2 between rats receiving either chronic desipramine treatment, or chronic fluoxetine 
Table 2 Demographic Data for Post-Mortem Brains

\begin{tabular}{|c|c|c|c|c|}
\hline Variable & Control $(n=15)$ & Schizophrenia $(n=14)$ & Bipolar disorder $(n=15)$ & Major depression $(n=15)$ \\
\hline Age (years, means $\pm S D$ ) & $48.1 \pm 10.7$ & $45.57 \pm 12.95$ & $42.3 \pm 11.7$ & $46.4 \pm 9.3$ \\
\hline Gender (male, female) & $9 M, 6 F$ & $8 \mathrm{M}, 6 \mathrm{~F}$ & $9 M, 6 F$ & $9 M, 6 F$ \\
\hline $\mathrm{PMI}(\mathrm{h}$, means $\pm S D)$ & $23.7 \pm 9.94$ & $33.79 \pm 15.16$ & $32.5 \pm 16.1$ & $27.5 \pm 10.7$ \\
\hline \multirow[t]{2}{*}{ Cause of death } & Cardiac: 13 & Cardiac: 8 & Cardiac: 4 & Cardiac: 7 \\
\hline & Accident: 2 & Accident:2 & Accident: I & Suicide: 7 \\
\hline $\mathrm{PH}$ (means $\pm \mathrm{SD})$ & $6.3 \pm 0.2$ & $6.2 \pm 0.25$ & $6.2 \pm 0.2$ & $6.2 \pm 0.2$ \\
\hline Brain hemisphere used (right:left) & $8: 7$ & $9: 5$ & $7: 8$ & $9: 6$ \\
\hline Lifetime antipsychotic dose ${ }^{a}(\mathrm{mg}$, means $\pm S D)$ & 0 & $52428.57 \pm 64401$ & $20827 \pm 24016$ & 0 \\
\hline
\end{tabular}

a Lifetime antipsychotic dose in fluphenazine milligram equivalents.

NA - not applicable.

a

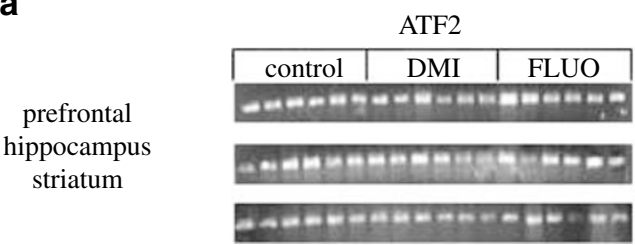

b

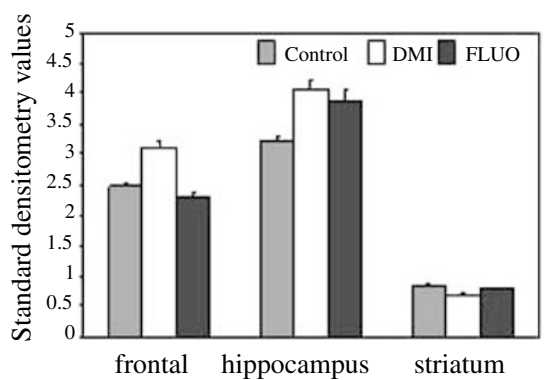

C

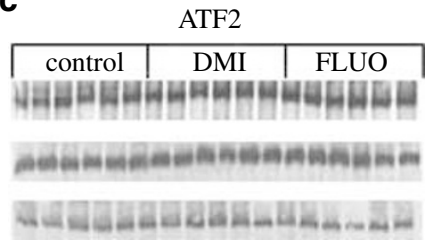

d

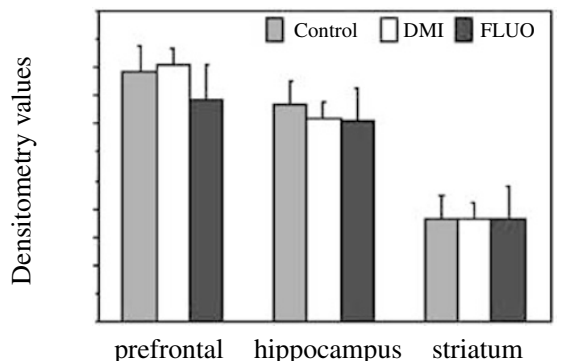

e

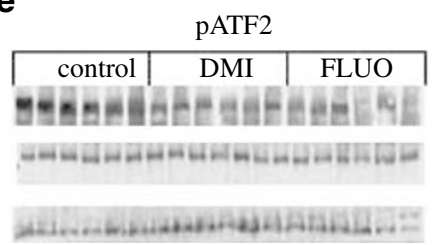

$\mathbf{f}$

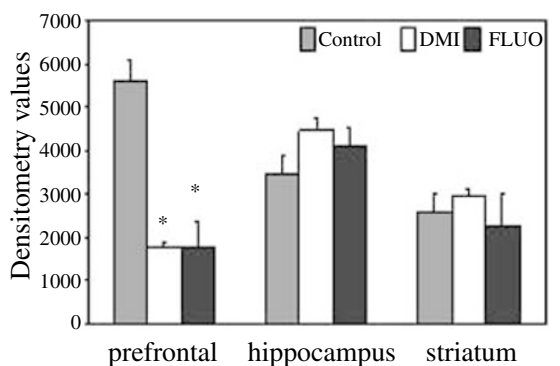

Figure $2 \mathrm{mRNA}$, protein levels, and phosphorylation levels of ATF2 in the prefrontal cortex, hippocampus, and striatum of chronically treated rats. RTPCR analysis of ATF2 mRNA expression in representative gels (a) and densitometry values standardized for $\beta$-actin (b). Western analysis of ATF2 protein level in representative gels (c) and densitometry values (d). Western analysis of pATF2 protein level in representative gels (e) and densitometry values ( $f$ ). Rats were treated for 21 consecutive days with $10 \mathrm{mg} / \mathrm{kg}$ desipramine (DMI) $(n=6), 5 \mathrm{mg} / \mathrm{kg}$ fluoxetine $(F L U O)(n=6)$, or saline $(\mathrm{control})(n=6)$. Densitometry values are means of three to four gels. The difference between means was analyzed by ANOVA followed by Dunnett post hoc tests. $* p<0.001$.

treatment, and control rats yielded a significant group effect in the frontal cortex $(\mathrm{F}=24.180, \mathrm{df}=2, p<0.0001)$, but not in the hippocampus or striatum $(\mathrm{F}=2.059, \mathrm{df}=2$, $p=0.167 ; \quad \mathrm{F}=3.393, \quad \mathrm{df}=2, \quad p=0.068, \quad$ respectively) (Figure 2). Bonferroni post hoc analysis showed that the difference in frontal cortex pATF2 levels between groups was a result of a significant three-fold decrease in pATF2 levels in rats receiving chronic desipramine treatment compared to control rats $(p<0.00001)$, as well as a similar decrease in rats receiving chronic fluoxetine treatment compared to control rats $(p<0.00001)$. Antidepressants treatment had no effect on the mRNA or protein levels of ATF2 (nonphosphorylated) in any of the brain regions tested.
mRNA, Protein Levels, and Phosphorylation Levels of ATF2 in a Chronic Unpredictable Stress Model

Rats, 4 months postexposure to the stress paradigm, exhibited a $134 \%$ increase in protein levels of pATF2 in the frontal cortex $(\mathrm{F}=4.565, \mathrm{df}=1, p<0.05)$, but not in the hippocampus and striatum $(\mathrm{F}=2.829, \mathrm{df}=1, p=0.189$; $\mathrm{F}=3.919, \mathrm{df}=1, p=0.064$ ) (Figure 3 ). This was paralleled by a $33 \%$ decrease in ATF2 protein levels in the frontal cortex $(\mathrm{F}=19.363, \mathrm{df}=1, p<0.0001)$, and not in the hippocampus or striatum $(\mathrm{F}=2.532, \mathrm{df}=1, p=0.143$; $\mathrm{F}=1.23, \mathrm{df}=1, p=0.243$, respectively). Stress exposure had no effect on the mRNA levels of ATF2 in any of the brain regions. 
a

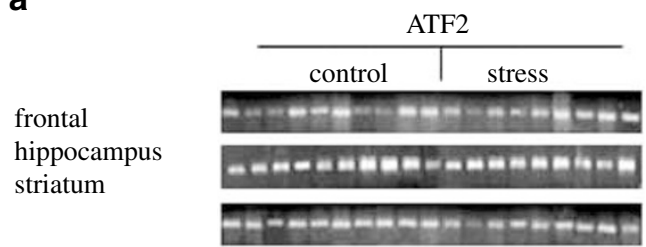

C

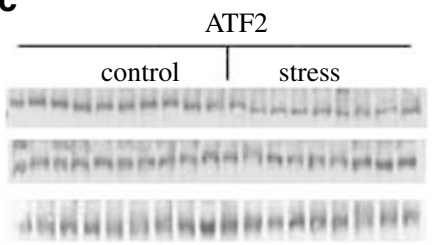

e

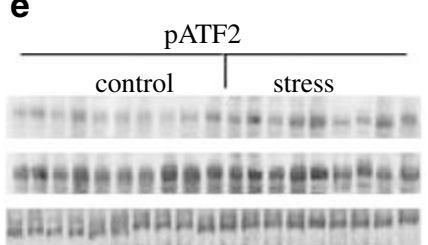

b

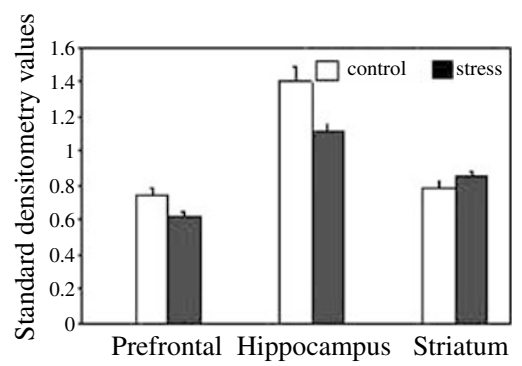

d

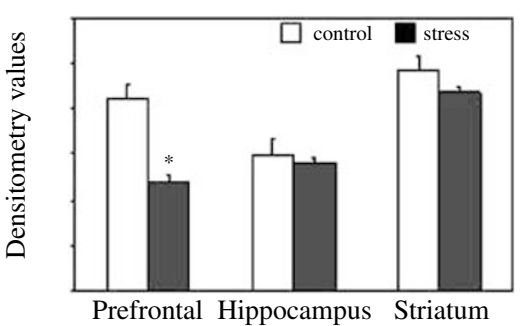

f

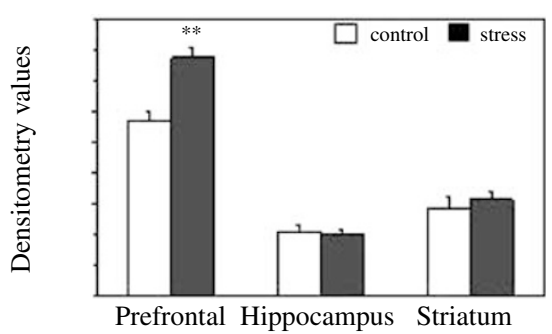

Figure 3 mRNA, protein levels, and phosphorylation levels of ATF2 in the prefrontal cortex, hippocampus, and striatum of rats exposed to prolonged stress. RT-PCR analysis of ATF2 mRNA expression in representative gels (a) and the corresponding densitometry values (b). Western analysis of ATF2 protein level in representative gels (c) and the corresponding densitometry values (d). Western analysis of pATF2 protein level (e) and the corresponding densitometry values (f). Rats were subjected to 6 weeks of variable unpredictable stressors ( $n=10 /$ group). Densitometry values are means of three to four gels. The difference between means was analyzed by ANOVA followed by Dunnett post hoc tests. $* p<0.01$, $* * * 0.05$.

\section{ATF2 Protein and Phosphorylation Levels in the Human Ventral Parieto-Occipital Cortex (BA 19).}

Frozen specimens from the parieto-occipital cortex of 59 human post-mortem brains, including 15 depressed patients, 15 bipolars, 14 schizophrenics, and 15 normal controls were compared for protein levels of ATF2 and pATF2. ANOVA showed that protein levels of ATF2 as well as pATF2 were similar in all groups $(\mathrm{F}=1.437, \mathrm{df}=3$, $p=\mathrm{NS} ; \mathrm{F}=0.338, \mathrm{df}=3, p=\mathrm{NS}$, respectively) (Figure 4). Interestingly, however, within the depressed group, a significant $34 \%$ reduction in pATF2 was observed in patients who had received antidepressant medications at the time of death ('medicated', $n=7$ ), compared to those not receiving antidepressants ('unmedicated', $n=8$ ) $(\mathrm{F}=4.977, \mathrm{df}=1, p=0.044)$ (Figure 5).

\section{Demographic Parameters, Covariance Analysis}

To control for potential confounds, age, gender, laterality, PMI, and brain $\mathrm{pH}$ were added as covariates and assessed by ANCOVA for protein levels of ATF2 and pATF2. ATF2 and pATF2 levels were not affected by any of these parameters, except for an effect of brain $\mathrm{pH}$ on pATF2 exclusively in the schizophrenic group. No significant correlation was observed between the onset and duration of disease as well as antipsychotic medication with either the protein levels of ATF2 or those of pATF2.

\section{DISCUSSION}

The modulation of transcription factors by various groups of antidepressants has been suggested as the downstream target in antidepressant activation of diverse signal transduction cascades. Such modulation is considered
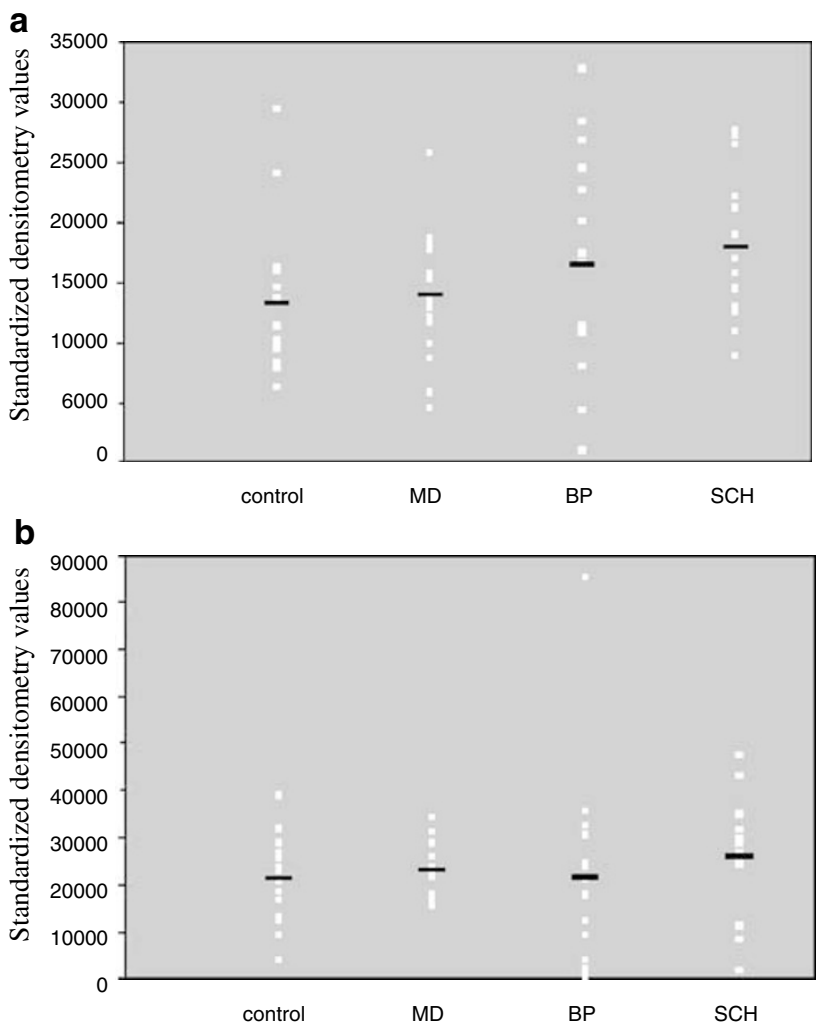

Figure 4 Protein levels of ATF2 (a) and PATF2 (b) in the ventral parieto-occipital cortex (B/A 19) of control subjects, depressed, bipolar, and schizophrenic patients. The dark lines represent the mean value for each group. The difference between means was analyzed by ANOVA.

important in the reversal of deleterious effects such as stress, which are thought to contribute to the pathophysiology of depression (D'sa and Duman, 2002). To date, the most extensively studied transcription factor involved in the 


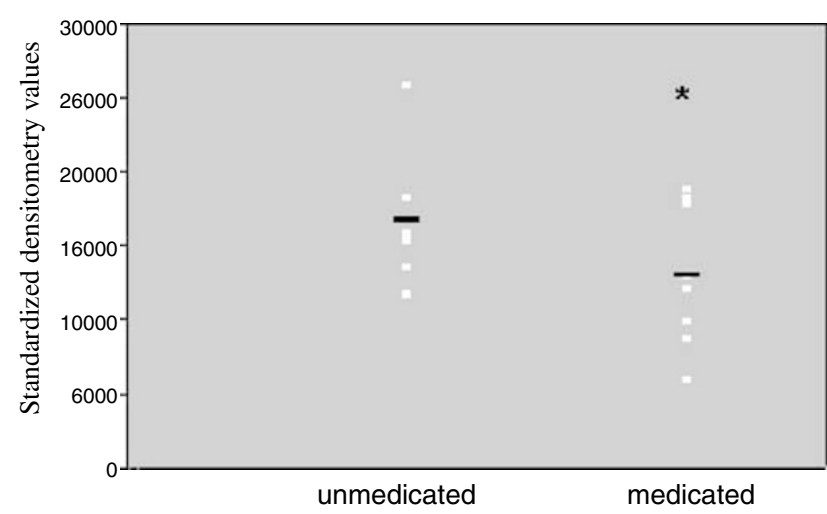

Figure 5 Protein levels of PATF2 in the ventral parieto-occipital cortex of medicated and unmedicated depressed patients. The dark lines represent the mean value for each group. The difference between means was analyzed by Mann-Whitney nonparametric analysis. ${ }^{*} p<0.05$.

etiology and treatment of depression has been CREB (Nibuya et al, 1996; Vaidya and Duman, 2001; Nestler et al, 2002). Given the multitude of postreceptor cascades initiated by antidepressants (Menkes et al, 1983; Duman et al, 1997; Popoli et al, 2000) as well as those involved in stress (Morrill et al, 1993; Huang et al, 2002), the involvement of additional transcription factors is anticipated.

In the present study, we report opposing effects of antidepressants and long-term consequences of stress on the phosphorylation of ATF2, which is a member of the CREB/ATF family of transcription factors. Thus, a decrease in PATF2 was observed in rat frontal cortex consequent to chronic treatment with either of two antidepressants, desipramine or fluoxetine. In contrast, exposure of rats to prolonged stress resulted in a frontal cortex increase in pATF2 4 months postexposure. Rats exposed to stress also presented a decrease in the frontal cortex protein levels of nonphosphorylated ATF2. The lack of a parallel decrease in the mRNA levels of ATF2 suggests that this is a posttranscriptional event, raising the possibility that this is a byproduct of increased ATF2 phosphorylation. Alternatively, the lack of an observed group effect in ATF2 mRNA may be due to the limitations inherent in the RT-PCR method, in which small differences between groups are difficult to detect. Still, the parallel lack of alteration in ATF2 mRNA and protein levels in all other brain regions supports the validity of the RT-PCR results.

The pATF2 alterations reported here were confined to the frontal cortex. No effect was observed in the hippocampus, which has also been strongly implicated in stress and depression (Sheline et al, 1996; Bremner et al, 2000). Accordingly, we have also shown reciprocal effects of similar stress exposure and antidepressants on the levels of pCREB (Laifenfeld et al, 2002a), which were also evident only in the frontal cortex. In the latter study, however, the effect was reversed. Antidepressants induced increases, while the stress induced decreases, in pCREB. The mutual regulation by antidepressants and stress of both members of this transcription factor family in the same brain region is interesting in several respects. First, it suggests the involvement of signal transduction pathways other than the cAMP-CREB pathway (for a review see Vaidya and
Duman, 2001; D'sa and Duman, 2002). Moreover, it points to the complexity of gene expression patterns involved in the etiology and therapeutics of depression, in as much as these entail concurrent up- and downregulations of genes with common motifs, that is, CREB and ATF2. It has been previously suggested that the control of gene expression in response to antidepressants and stress relies on the interplay between different transcription factors (D'sa and Duman, 2002). In fact, there is evidence suggesting that the simultaneous binding of CREB and ATF2 to other transcription factors may serve to modulate the latter's activity (Edelman et al, 2000). Conceivably, the transcription of downstream genes relevant to depression is dependent upon some type of equilibrium between these two family members.

ATF2 is activated by the p38-MAPK pathway, also known as the stress-activated MAPK, and has been shown to be induced by cellular stressors such as heat shock, UVirradiation, and hyperosmolarity (Adler et al, 1995; Laderoute et al, 1999). The results of the present study indicate that ATF2 activation is not limited to stressors at the cellular level, but rather is part of a general response to exposure to stressors at different levels of the organism, prevailing long after cessation of the stressors, a notion previously raised by Mehta and Miller (1999). In fact, Sapolsky (2000) proposes a mechanism whereby psychological stress results in glutamate excitotoxicity, disturbed calcium homeostasis, an inhibition of glucose transport, and an increase in oxygen radical generation. Similar processes could be the intermediates between the aftermath of chronic stress exposure in the present study and induction of ATF2 phosphorylation.

ATF2 phosphorylation is also induced by cytokines, in particular IL-1 $\beta$ and TNF- $\alpha$ (Gupta et al, 1995; Clerk et al, 1999), which have recently been implicated in depression. Thus, raised levels of several proinflammatory cytokines, including IL-1R, IL- 6 , and TNF- $\alpha$ have been described in clinical depression (Maes et al, 1995), and, likewise, stress has been linked with an increase in IL-1R, IL-6, and TNF- $\alpha$ (Maes et al, 1998; Steptoe et al, 2001). Conversely, several diverse antidepressants were found to decrease significantly monocyte production of IL-1, IL-6, and TNF- $\alpha$ in vitro (Xia et al, 1996), and antidepressant-induced IL-1 antagonistic activity was also observed in rat brain (Licinio and Wong, 1999). Increased levels of these cytokines in stress, therefore, could bring about the increase observed in pATF2 in the present study. In contrast, cytokine downregulation by antidepressants is a compelling account for the antidepressant-induced reduction we saw in ATF2 phosphorylation. Interestingly, antidepressant effect on pATF2 was obtained with both antidepressants, regardless of their pharmacological effects; desipramine is a noradrenergic tricyclic, while fluoxetine is a serotonergic specific agent. The convergence of both antidepressants on pATF2 regulation suggests the relevance of this transcription factor as a common downstream mediator of their antidepressant mode of action.

Cytokine signaling via ATF2 phosphorylation has been found to lead to apoptosis (Faris et al, 1998; Ammendrup et al, 2000), and ATF2 is reported to elevate levels of UVCinduced apoptosis (Ivanov and Ronai, 1999), as well as apoptosis consequent to thiol depletion (Aoshiba et al, 1999). There is some evidence directly linking depression 
with the processes of apoptosis (Licinio and Wong, 1999), including hippocampal apoptosis in post-mortem brains of depressed patients (Lucassen et al, 2001), and increased apoptosis in the peripheral blood of patients with major depression (Eilat et al, 1999). Induction of pATF2 by chronic stress in the present paradigm, particularly in the frontal cortex, could provide a mechanism through which long-term stress predisposes cells to apoptosis, and may be relevant to the etiology of depression. Several lines of evidence support the latter notion. For example, in the frontal cortex, there are reports of abnormalities in brain volume and metabolism in post-mortem brains of depressed patients (Drevets et al, 1997; Rajkowska et al, 1999; Rajkowska 2000; Manji et al, 2001). In addition, animal models of depression indicate decreased cell survival in stress, which may provide a cellular basis for the impairments observed in depressed patients (Czeh et al, 2002). Conversely, the antidepressant-induced decrease in an ATF2-dependent cascade may be conducive to the enhancement of neuronal resilience by antidepressants as previously suggested (D'sa and Duman, 2002), as well as to the reversal of damaging effects of stress. Direct assessment of the latter notion is currently underway through the examination of the interaction between stress and antidepressant medications on the expression of ATF2.

In order to assess the relevance of our findings in animal models to depression in humans, we examined the ATF2 expression in human post-mortem brains of depressed, bipolar, and schizophrenic patients, and normal controls. This was assessed in the ventral parieto-occipital cortex, alterations in which have been observed in depression (Ogura et al, 1998; Drevets et al, 2000; Brody et al, 2001). In the present study, no differences were observed in the levels of ATF2 and its phosphorylation between any of the patients groups. Interestingly, however, specifically in the depressed patients group, there was a significant medication effect on phosphorylated ATF2, which is concordant with the alterations found in the animal paradigms. Thus, the medicated patients presented lower levels of ATF2 phosphorylation compared with the nonmedicated ones. The specificity of alterations to depression was further supported by a lack of similar effects of antipsychotic medications. Arguably, this may suggest an antidepressant-induced decrease in PATF2, resulting in normalization of ATF2 phosphorylation levels, which may have been initially elevated in the depressed patients. We did not, however, observe a significant increase in pATF2 in nonmedicated depressed patients compared to normal controls. Li et al (2003) have recently shown that postmortem interval (PMI) produces profound and relatively rapid effects on the phosphorylation of proteins involved in intracellular signaling, including specifically the phosphorylation of ATF2. The inclusion of PMI as a covariate in our model did not result in a significant effect, indicating that differences in PMI between groups could not account for the lack of effect observed. Long PMIs could, however, result in all overdiminished levels in pATF2, hindering our ability to observe existing differences. Still, the average PMI levels did not differ significantly between medicated and unmedicated depressed patients (mean $\pm \mathrm{SD}=32.28 \pm 9.19$, $23 \pm 10.68$, respectively. $T=1.760, p=0.105$ ), and thus could not account for the observed decrease in PATF in medicated patients. Notably, the lack of differences in ATF2 levels could also be a result of the specificity of the region examined. Thus, while, as mentioned, alterations in the parietal cortex in general have been reported in depression (Ogura et al, 1998; Drevets et al, 2000; Brody et al, 2001), the select nature of the area we obtained (ie the ventral parietooccipital cortex) may have resulted in an attenuated effect. Conceivably, alterations in ATF2 would have been more prominent in regions more fundamental to the pathophysiology of the disorder.

In conclusion, our findings suggest that ATF2, like CREB, might be involved in the pathophysiology of depression and its pharmacotherapy, further highlighting the complexity and multitude of signal transduction pathways involved in this disorder.

\section{ACKNOWLEDGEMENTS}

This work was supported in part by a grant from Chief Scientist Israel Ministry of Health and by a grant from The Rambam Medical Center Research and Development Fund.

\section{REFERENCES}

Adler V, Fuchs SY, Kim J, Kraft A, King MP, Pelling J et al (1995). jun-NH2-terminal kinase activation mediated by UV-induced DNA lesions in melanoma and fibroblast cells. Cell Growth Differ 6: 1437-1446.

Ainsworth K, Smith SE, Zetterstrom TS, Pei Q, Franklin M, Sharp T (1998). Effect of antidepressant drugs on dopamine D1 and D2 receptor expression and dopamine release in the nucleus accumbens of the rat. Psychopharmacology (Berlin) 140: 470-477.

Ammendrup A, Maillard A, Nielsen K, Aabenhus AN, Serup P, Dragsbaek MO et al (2000). The c-Jun amino-terminal kinase pathway is preferentially activated by interleukin-1 and controls apoptosis in differentiating pancreatic beta-cells. Diabetes 49: $1468-1476$.

Aoshiba K, Yasui S, Nishimura K, Nagai A (1999). Thiol depletion induces apoptosis in cultured lung fibroblasts. Am J Respir Cell Mol Biol 21: 54-64.

Barrot M, Olivier JD, Perrotti LI, DiLeone RJ, Berton O, Eisch AJ et al (2002). CREB activity in the nucleus accumbens shell controls gating of behavioral responses to emotional stimuli. Proc Natl Acad Sci USA 99: 11435-11440.

Boyer PA, Skolnick P, Fossom LH (1998). Chronic administration of imipramine and citalopram alters the expression of NMDA receptor subunit mRNAs in mouse brain. A quantitative in situ hybridization study. J Mol Neurosci 10: 219-233.

Brady LS, Gold PW, Herkenham M, Lynn AB, Whitfield Jr HJ (1992). The antidepressants fluoxetine, idazoxan and phenelzine alter corticotropin-releasing hormone and tyrosine hydroxylase mRNA levels in rat brain, therapeutic implications. Brain Res 572: 117-125.

Bremner JD, Narayan M, Anderson ER, Staib LH, Miller HL, Charney DS (2000). Hippocampal volume reduction in major depression. Am J Psychiatry 157: 115-118.

Brody AL, Barsom MW, Bota RG, Saxena S (2001). Prefrontalsubcortical and limbic circuit mediation of major depressive disorder. Semin Clin Neuropsychiatry 6: 102-112.

Chuang DM, Chen RW, Chalecka-Franaszek E, Ren M, Hashimoto $\mathrm{R}$, Senatorov V et al (2002). Neuroprotective effects of lithium in cultured cells and animal models of diseases. Bipolar Disord 4: 129-136. 
Clerk A, Harrison JG, Long CS, Sugden PH (1999). Proinflammatory cytokines stimulate mitogen-activated protein kinase subfamilies, increase phosphorylation of c-Jun and ATF2 and upregulate c-Jun protein in neonatal rat ventricular myocytes. J Mol Cell Cardiol 31: 2087-2099.

Consogno E, Racagni G, Popoli M (2001). Modifications in brain CaM kinase II after long-term treatment with desmethylimipramine. Neuropsychopharmacology 24: 21-30.

Czeh B, Welt T, Fischer AK, Erhardt A, Schmitt W, Muller MB et al (2002). Chronic psychosocial stress and concomitant repetitive transcranial magnetic stimulation: effects on stress hormone levels and adult hippocampal neurogenesis. Biol Psychiatry 52: $1057-1065$.

De Cesare D, Fimia GM, Sassone-Corsi P (1999). Signaling routes to CREM and CREB plasticity in transcriptional activation. Trends Biochem Sci 24: 281-285.

Dowlatshahi D, MacQueen GM, Wang JF, Young LT (1998). Increased temporal cortex CREB concentrations and antidepressant treatment in major depression. Lancet 352: 1754-1755.

Drevets WC, Frank E, Price JC, Kupfer DJ, Greer PJ, Mathis C (2000). Serotonin type-1A receptor imaging in depression. $\mathrm{Nucl}$ Med Biol 27: 499-507.

Drevets WC, Price JL, Simpson JR, Todd RD, Reich T, Vannier M et al (1997). Subgenual prefrontal cortex abnormalities in mood disorders. Nature 386: 824-827.

D'Sa C, Duman RS (2002). Antidepressants and neuroplasticity. Bipolar Disord 4: 183-194.

Duman RS, Heninger GR, Nestler EJ (1997). A molecular and cellular theory of depression. Arch Gen Psychiatry 54: 597-606.

Edelman DB, Meech R, Jones FS (2000). The homeodomain protein Barx2 contains activator and repressor domains and interacts with members of the CREB family. J Biol Chem 275: 21737-21745.

Eilat E, Mendlovic S, Doron A, Zakuth V, Spirer Z (1999). Increased apoptosis in patients with major depression. A preliminary study. J Immunol 163: 533-534.

Faris M, Latinis KM, Kempiak SJ, Koretzky GA, Nel A (1998). Stress-induced Fas ligand expression in $\mathrm{T}$ cells is mediated through a MEK kinase 1-regulated response element in the Fas ligand promoter. Mol Cell Biol 18: 5414-5424.

Ferrer I, Blanco R, Carmona M, Puig B, Dominguez I, Vinals F (2002). Active, phosphorylation-dependent MAP kinases, MAPK/ERK, SAPK/JNK and p38, and specific transcription factor substrates are differentially expressed following systemic administration of kainic acid to the adult rat. Acta Neuropathol (Berl) 103: 391-407.

Flint KJ, Jones NC (1991). Differential regulation of three members of the ATF/CREB family of DNA-binding proteins. Oncogene 6: 2019-2026.

Grauer E (1998). Long-term behavioral effects of stress in rats: possible animal models of post traumatic stress disorder. In Levy A, Grauer E, Ben-Nathan D, de Kloet ER (eds). New Frontiers in Stress Research Modulation of Brain Function. Introduction to the Biology of Stress. Harwood Academic Chur: Switzerland, pp 225-233.

Gupta S, Campbell D, Derijard B, Davis RJ (1995). Transcription factor ATF2 regulation by the JNK signal transduction pathway. Science 267: 389-393.

Holahan CJ, Moos RH (1991). Life stressors, personal and social resources, and depression: a 4-year structural model. J Abnorm Psychol 100: 31-38.

Huang LT, Holmes GL, Lai MC, Hung PL, Wang CL, Wang TJ et al (2002). Maternal deprivation stress exacerbates cognitive deficits in immature rats with recurrent seizures. Epilepsia 43: $1141-1148$.

Ivanov VN, Ronai Z (1999). Down-regulation of tumor necrosis factor alpha expression by activating transcription factor 2 increases UVC-induced apoptosis of late-stage melanoma cells. J Biol Chem 274: 14079-14089.
Karin M, Hunter T (1995). Transcriptional control by protein phosphorylation: signal transmission from the cell surface to the nucleus. Curr Biol 5: 747-757.

Kendler KS, Kessler RC, Walters EE, Maclean C, Neale MC, Heath AC, Eaves LJ (1995). Stressful life events, genetic liability, and onset of an episode of major depression in women. Am J Psychiatry 152: 833-842.

Laderoute KR, Mendonca HL, Calaoagan JM, Knapp AM, Giaccia AJ, Stork PJ (1999). Mitogen-activated protein kinase phosphatase-1 (MKP-1) expression is induced by low oxygen conditions found in solid tumor microenvironments. A candidate MKP for the inactivation of hypoxia-inducible stress-activated protein kinase/c-Jun N-terminal protein kinase activity. J Biol Chem 274 12890-12897.

Laifenfeld D, Karry R, Grauer E, Klein E, Ben-Shachar D (2002a). Antidepressants and stress modulate the expression and protein levels of two genes involved in neuronal plasticity, CAM-L1 and laminin in rat brain. Israel J Psychiatry 39: 36.

Laifenfeld D, Klein E, Karry R, Ben-Shachar D (2002b). Norepinephrine regulated genes involved in plasticity, CAM-L1 and CREB, are altered in post mortem brains of depressed patients. Neural Plasticity 9: 95.

Li XY (2001). Rapid activation of p38 mitogen-activated protein kinase by corticosterone in PC12 cells. Sheng Li Xue Bao 53: 414-418.

Li J, Gould TD, Yuan P, Manji HK, Chen G (2003). Post-mortem interval effects on the phosphorylation of signaling proteins. Neuropsychopharmacology 28: 1017-1025.

Licinio J, Wong ML (1999). The role of inflammatory mediators in the biology of major depression: central nervous system cytokines modulate the biological substrate of depressive symptoms, regulate stress-responsive systems, and contribute to neurotoxicity and neuroprotection. Mol Psychiatry 4: 317-327.

Lowther S, Katona CL, Crompton MR, Horton RW (1997). Brain $\left[{ }^{3} \mathrm{H}\right]$ cAMP binding sites are unaltered in depressed suicides, but decreased by antidepressants. Brain Res 758: 223-228.

Lucassen PJ, Muller MB, Holsboer F, Bauer J, Holtrop A, Wouda J et al (2001). Hippocampal apoptosis in major depression is a minor event and absent from subareas at risk for glucocorticoid overexposure. Am J Pathol 158: 453-468.

Maekawa T, Sakura H, Kanei-Ishii C, Sudo T, Yoshimura T, Fujisawa J et al (1989). Leucine zipper structure of the protein CRE-BP1 binding to the cyclic AMP response element in brain. EMBO J 8: 2023-2028.

Maes M, Meltzer HY, Bosmans E, Bergmans R, Vandoolaeghe E, Ranjan $\mathrm{R}$ et al (1995). Increased plasma concentrations of interleukin-6, soluble interleukin-6, soluble interleukin-2 and transferrin receptor in major depression. J Affect Disord 34: 301-309.

Maes M, Song C, Lin A, De Jongh R, Van Gastel A, Kenis G et al (1998). The effects of psychological stress on humans increased production of pro-inflammatory cytokines and a Th1-like response in stress-induced anxiety. Cytokine 10: 313-318.

Makino H, Masaka M, Matsushima Y, Kanatsuka A, Yamoto M, Kumagai A (1975). Effects of ACTH, dexamethasone, adrenalectomy and stress on cAMP content of adenohypophysis and adrenals in rats. Endocrinol Jpn 22: 373-377.

Manji HK, Drevets WC, Charney DS (2001). The cellular neurobiology of depression. Nat Med 7: 541-547.

Mayr B, Montminy M (2001). Transcriptional regulation by the phosphorylation-dependent factor CREB. Nat Rev Mol Cell Biol 2: 599-609.

Mehta KD, Miller L (1999). Inhibition of stress-activated p38 mitogen-activated protein kinase induces low-density lipoprotein receptor expression. Trends Cardiovasc Med 9: 201-205.

Menkes DB, Rasenick MM, Wheeler MA, Bitensky MW (1983). Guanosine triphosphate activation of brain adenylate cyclase enhancement by long-term antidepressant treatment. Science 219: $65-67$. 
Morishita S, Aoki S (2002). Effects of tricyclic antidepressants on protein kinase $\mathrm{C}$ activity in rabbit and human platelets in vivo. J Affect Disord 70: 329-332.

Morrill AC, Wolfgang D, Levine MA, Wand GS (1993). Stress alters adenylyl cyclase activity in the pituitary and frontal cortex of the rat. Life Sci 53: 1719-1727.

Nestler EJ, Barrot M, DiLeone RJ, Eisch AJ, Gold SJ, Monteggia LM (2002). Neurobiology of depression. Neuron 34: 13-25.

Nestler EJ, McMahon A, Sabban EL, Tallman JF, Duman RS (1990). Chronic antidepressant administration decreases the expression of tyrosine hydroxylase in the rat locus coeruleus. Proc Natl Acad Sci USA 87: 7522-7526.

Nestler EJ, Terwilliger RZ, Duman RS (1989). Chronic antidepressant administration alters the subcellular distribution of cyclic AMP-dependent protein kinase in rat frontal cortex. $J$ Neurochem 53: 1644-1647.

Nibuya M, Nestler EJ, Duman RS (1996). Chronic antidepressant administration increases the expression of cAMP response element binding protein (CREB) in rat hippocampus. $J$ Neurosci 16: $2365-2372$.

Ogura A, Morinobu S, Kawakatsu S, Totsuka S, Komatani A (1998). Changes in regional brain activity in major depression after successful treatment with antidepressant drugs. Acta Psychiatr Scand 98: 54-59.

Ouwens DM, de Ruiter ND, van der Zon GC, Carter AP, Schouten J, van der Burgt C et al (2002). Growth factors can activate ATF2 via a two-step mechanism: phosphorylation of Thr71 through the Ras-MEK-ERK pathway and of Thr69 through RalGDS-Srcp38. EMBO J 21: 3782-3793.

Perez J, Tinelli D, Bianchi E, Brunello N, Racagni G (1991). cAMP binding proteins in the rat cerebral cortex after administration of selective 5-HT and NE reuptake blockers with antidepressant activity. Neuropsychopharmacology 4: 57-64.

Perez J, Tinelli D, Brunello N, Racagni G (1989). cAMP-dependent phosphorylation of soluble and crude microtubule fractions of rat cerebral cortex after prolonged desmethylimipramine treatment. Eur J Pharmacol 172: 305-316.

Pham TA, Impey S, Storm DR, Stryker MP (1999). CRE-mediated gene transcription in neocortical neuronal plasticity during the developmental critical period. Neuron 22: 63-72.

Pliakas AM, Carlson RR, Neve RL, Konradi C, Nestle EJ, Carlezon WA (2001). Altered responsiveness to cocaine and increased immobility in the forced swim test associated with elevated
cAMP response element-binding protein expression in nucleus accumbens. J Neurosci 21: 7397-7403.

Popoli M, Brunello N, Perez J, Racagni G (2000). Second messenger-regulated protein kinases in the brain: their functional role and the action of antidepressant drugs. J Neurochem 74: $21-33$

Rajkowska G (2000). Postmortem studies in mood disorders indicate altered numbers of neurons and glial cells. Biol Psychiatry 48: 766-777.

Rajkowska G, Miguel-Hidalgo JJ, Wei J, Dilley G, Pittman SD, Meltzer HY et al (1999). Morphometric evidence for neuronal and glial prefrontal cell pathology in major depression. Biol Psychiatry 45: 1085-1098.

Sapolsky RM (2000). The possibility of neurotoxicity in the hippocampus in major depression: a primer on neuron death. Biol Psychiatry 48: 755-765.

Sheline YI, Wang PW, Gado MH, Csernansky JG, Vannier MW (1996). Hippocampal atrophy in recurrent major depression. Proc Natl Acad Sci USA 93: 3908-3913.

Steptoe A, Willemsen G, Owen N, Flower L, Mohamed-Ali V (2001). Acute mental stress elicits delayed increases in circulating inflammatory cytokine levels. Clin Sci (London) 101: 185-192.

Suzuki T, Yamakuni T, Hagiwara M, Ichinose H (2002). Identification of ATF-2 as a transcriptional regulator for the tyrosine hydroxylase gene. J Biol Chem 277: 40768-40774.

Trentani A, Kuipers SD, Ter Horst GJ, Den Boer JA (2002). Selective chronic stress-induced in vivo ERK1/2 hyperphosphorylation in medial prefrontocortical dendrites implications for stress-related cortical pathology? Eur J Neurosci 15: 1681-1691.

Vaidya VA, Duman RS (2001). Depresssion-emerging insights from neurobiology. Br Med Bull 57: 61-79.

Vedder H, Bening-Abu-Shach U, Lanquillon S, Krieg JC (1999). Regulation of glucocorticoid receptor-mRNA in human blood cells by amitriptyline and dexamethasone. J Psychiatr Res 33: 303-308.

Willner P (1997). The mesolimbic dopamine system as a target for rapid antidepressant action. Int Clin Psychopharmacol (Suppl 3): $7-14$.

Xia Z, DePierre JW, Nassberger L (1996). Tricyclic antidepressants inhibit IL-6, IL-1 beta and TNF-alpha release in human blood monocytes and IL-2 and interferon-gamma in T cells. Immunopharmacology 34: 27-37. 